\title{
Learning from Interactions with Prisoners
}

\section{Authors;}

Izabella Smolicz* (1), Jonathan Mayhew (2), Faye Gishen (2,3)

\author{
Affiliations; \\ (1) University College London Great Ormond Street Institute of Child Health, London, \\ United Kingdom \\ (2) Clinical and Professional Practice Department, University College London Medical \\ School, London, United Kingdom \\ (3) Royal Free London NHS Foundation Trust, London United Kingdom \\ *Corresponding author: izabella.smolicz.16@ucl.ac.uk
}

During my first clinical year of medical school I (IS) was asked to perform an initial assessment of a patient in the Emergency Department; what I did not know was that the patient was a prisoner, in handcuffs, and accompanied by prison officers. It was the first time I had been involved in a prisoner's care and the staff had little advice to offer apart from advising me to stay close to the door. When taking a history from the patient about analgesic use and alcohol intake, the patient and prison guards laughed as analgesics (unless prescribed) and alcohol are prohibited in prison.

I approached this clerking as I would with any patient, but the experience left me feeling unprepared for future similar encounters. It ignited my interest and desire to share my reflections with my peers, with the intention of improving both learning in this area and patient 
care. Therefore, I approached faculty members (authors JM, FG) who oversee professionalism and communication within the medical school curriculum with my reflections, as their input is vital in making any curricular changes.

In conjunction with co-authors JM and FG, we conducted a literature review to explore whether any guidance exists for medical students with specific reference to interacting with prisoners. Guidelines published by the British Medical Association (BMA) in 2009 were found. These emphasise that low risk patients should not be restrained or have officers present when being examined, and that the risk regarding escape and violence should be assessed prior to a patient coming to hospital (1). Healthcare professionals can, in certain circumstances, ask for restraints to be removed. The seniority of doctors who should be involved in treating prisoners attending hospital is not addressed in the BMA guidelines. However, the Royal College of Emergency Medicine recommends that only more senior doctors, from middle grades upwards, see patients in police custody (2).

Tuite et al conducted a survey in 2006 in Dublin looking at doctors' knowledge of the BMA guidance. Of the doctors who responded, $98 \%$ were unaware of existing guidance, $60 \%$ did not feel comfortable during the clinical examination of prisoners and only $3 \%$ felt confidentiality was never breached (3). However, there may be many factors affecting a doctor's decision to leave restraints in place or keep officers present during a consultation, such as the perceived threat of violence or escape. In addition, this study did not explore the knowledge of guidance for other healthcare professionals, if available. Ultimately, we suggest there may be an association between doctors' lack of awareness of guidelines, and confidentiality breaches (3). If doctors are generally unaware of these guidelines, it is unlikely that medical students will be. 
Medical undergraduate curricula in the United Kingdom (UK) and internationally include limited opportunities for medical students to gain experience of healthcare for prisoners within prisons (4). Opportunities to engage with prisoners include shadowing forensic psychiatrists, participating in general practice placements within prisons and delivering seminars to prisoners as part of student selected component (SSC) projects, where SSCs are optional modules in the UK medical school curriculum that students choose to study based on personal interests (5).

Baguley et al produced a report commissioned by the Department of Health, which investigated placement opportunities for healthcare students within UK prisons (6). The report demonstrated that nursing education currently has the most learning opportunities in prisons. There were 55 prisons offering adult nursing placements and 58 prisons offering mental health nursing placements, in comparison to 12 prisons offering medical student placements. The report highlighted the importance of having multidisciplinary placements for the benefit of staff, students and prisoners, with prisoners often having more complex health needs compared to the general population. In addition, collaboration between prisons and higher education institutions was emphasised, with particular emphasis on those involved in placements having the training and information they needed. An example suggested was providing courses for supervisors and induction packs for students (6). However, it is not clear how healthcare students experience the care of prisoners in hospital, if at all during their training.

Medical students may be the first members of the healthcare team to assess a prisoner. Their knowledge of existing guidance is important and dedicated guidance for medical and other healthcare students may be useful if they are involved in the clinical care of a prisoner during their career. We therefore propose and formulate dedicated guidance for medical students 
(Figure 1). This could be introduced in a formal teaching session in the curriculum or be made available as a reference resource.

To conclude, this learning experience was valuable and provided a stimulus to propose guidance for medical students to refer to during their clinical education. All patients are entitled to the same level of healthcare and it is important to reserve judgements and acknowledge unconscious and conscious biases. This guidance will hopefully aid medical students in feeling more informed and supported, which could in turn, lead to improved care of prisoners.

\section{References}

1. British Medical Association. The medical role in restraint and control: custodial settings. Available from: https://www.bma.org.uk/-/media/files/pdfs/practical advice at work/ethics/medicalrolerestraintaug2009.pdf [Accessed 18 March 2017].

2. The Royal College of Emergency Medicine. Emergency Department Patients in Police Custody. Available from: https://www.rcem.ac.uk/docs/College Guidelines/5n. ED Patients in Police Custody (revised June 2016).pdf [Accessed 2 October 2017].

3. Tuite H, Browne K, O'Neill D. Prisoners in general hospitals: doctors' attitudes and practice. BMJ. 2006;332(7540):548-9.

4. Alemagno SA, Wilkinson M, Levy L. Medical education goes to prison: why? Acad Med. 2004;79(2):123-7.

5. Brooker R, Hu W, Reath J, Abbott P. Medical student experiences in prison health services and social cognitive career choice: a qualitative study. BMC Med Educ. 2018;18(1):3 
6. Baguley I, Gallon I, Alexander J, McGonagle I. Crossing Boundaries.

Multidisciplinary Health and Social Care Provision in Prison Health. 2006. Available from:

http://s3.amazonaws.com/zanran_storage/www.hsmc.bham.ac.uk/ContentPages/43213445.pd

f [Accessed 19 November 2017].

All authors gave final approval to the submitted paper.

The authors confirm no funding was sourced.

The authors report no declarations of interest.

Ethical approval was not sought for this piece, as this is a reflective piece only. 